\title{
Performance of shear-waves elastography in the non-invasive assessment of liver fibrosis in chronic hepatitis in the Romanian population
}

\author{
Monica Andreea Stoica ${ }^{1 *}$, Anca Streinu-Cercel ${ }^{1,2}$, Oana Săndulescu ${ }^{1,2}$, Liliana Lucia Preoțescu ${ }^{1,2}$, Gabriela Ceapraga ${ }^{1}$, \\ Adrian Streinu-Cercel ${ }^{1,2}$ \\ From The 10th Edition of the Scientific Days of the National Institute for Infectious Diseases "Prof Dr Matei \\ Bals" \\ Bucharest, Romania. 15-17 October 2014
}

\section{Background}

Liver fibrosis is one of the major factors associated with progression of liver disease in chronic HBV [1] or HCV $[2,3]$ infection, but also in metabolic diseases with impact on the liver.

\section{Methods}

We have performed a study to determine liver stiffness in patients with chronic hepatitis in Romania. One trained operator performed shear-waves elastography (SWE) using Aixplorer (SuperSonic Imagine, Aix-enProvence, France) in all consecutive patients monitored in our clinic over the course of 7 months, from January 2014 to July 2014.

\section{Results}

We have examined a total of 80 patients with chronic hepatitis, of which $58.8 \%$ had HCV infection, $16.3 \%$ HBV infection, $6.3 \% \mathrm{HBV}+\mathrm{HDV}$ coinfection, $2.5 \%$ ASH, 2.5\% HIV infection and 13.8\% had idiopathic liver involvement. The male-to-female ratio was $0.86: 1$, and the mean age was $48.6 \pm 14.9$ years.

The mean duration of hepatic disease evolution was 7.6 \pm 5.7 years, longer for HCV infection (mean $8.3 \pm 5.9$ years) than for HBV infection ( $4.75 \pm 3.9$ years, $\mathrm{p}=0.028$ ). The overall mean SWE liver stiffness was $9.6 \pm 5.3 \mathrm{kPa}$, higher in patients with $\mathrm{HCV}$ infection $(10.8 \pm 5.9 \mathrm{kPa})$ than in those with HBV infection $(6.98 \pm 1.9 \mathrm{kPa}, \mathrm{p}=$

\footnotetext{
* Correspondence: monicandreea@yahoo.com

"National Institute for Infectious Diseases "Prof. Dr. Matei Balş", Bucharest, Romania

Full list of author information is available at the end of the article
}

0.009). Overall, $37.5 \%$ of patients were classified as F0-F1 on SWE, 25.0\% F2, 8.8\% F3 and 28.7\% F4.

Liver cirrhosis was present in $28.7 \%$ of patients and hepatocellular carcinoma had already been diagnosed in $6.3 \%$ of all patients and in $21.7 \%$ of all patients with cirrhosis ( 5 cases, of which 4 had been previously diagnosed with cirrhosis with HCV - 3 cases, and HBV $+\mathrm{HDV}-1$ case, and 1 had an idiopathic cause for liver involvement and a stiffness corresponding to F0-F1 on SWE).

\section{Conclusion}

There seem to be significant differences between two of the main groups of patients examined, with a longer duration of infection and an accordingly higher liver stiffness in the chronic HCV group, when compared to the chronic HBV group.

\section{Acknowledgement \\ This paper is partially supported by the Sectoral Operational Programme Human Resources Development (SOP HRD), financed from the European Social Fund and by the Romanian Government under the contract numbers POSDRU/159/1.5/S/137390.}

\section{Authors' details}

${ }^{1}$ National Institute for Infectious Diseases "Prof. Dr. Matei Balş", Bucharest, Romania. ${ }^{2}$ Carol Davila University of Medicine and Pharmacy, Bucharest, Romania.

\section{Published: 15 October 2014}

\section{References}

1. Streinu-Cercel A: Hepatitis B in the spotlight. GERMS 2011, 1:5.

2. Ferraioli G, Parekh $P$, Levitov AB, Filice C: Shear wave elastography for evaluation of liver fibrosis. J Ultrasound Med 2014, 33:197-203.

3. Streinu-Cercel A: Hepatitis C in the interferon-free era. GERMS 2013, 3:114. 
doi:10.1186/1471-2334-14-S7-015

Cite this article as: Stoica et al:: Performance of shear-waves

elastography in the non-invasive assessment of liver fibrosis in chronic

hepatitis in the Romanian population. BMC Infectious Diseases 201414

(Suppl 7):015.

Submit your next manuscript to BioMed Central and take full advantage of:

- Convenient online submission

- Thorough peer review

- No space constraints or color figure charges

- Immediate publication on acceptance

- Inclusion in PubMed, CAS, Scopus and Google Scholar

- Research which is freely available for redistribution

Submit your manuscript at 